\title{
A Meta-Analysis of the Relationship between Customer Misbehavior and Emotional Labor
}

\author{
Hui Man1, Feiyan Liu1, Yutong Gao² \\ ${ }^{1}$ School of Business, Nanjing Normal University, Nanjing, China \\ ${ }^{2}$ Business and Economics Faculty, Monash University, Melbourne, Australia \\ Email:2271468089@qq.com
}

How to cite this paper: Man, H., Liu, F.Y. and Gao, Y.T. (2017) A Meta-Analysis of the Relationship between Customer Misbehavior and Emotional Labor. Open Journal of Social Sciences, 5, 150-162. https://doi.org/10.4236/jss.2017.56014

Received: May 19, 2017

Accepted: June 17, 2017

Published: June 20, 2017

Copyright (c) 2017 by authors and Scientific Research Publishing Inc. This work is licensed under the Creative Commons Attribution International License (CC BY 4.0).

http://creativecommons.org/licenses/by/4.0/

\section{(c) (i) Open Access}

\begin{abstract}
A meta-analysis was used to aggregate results from studies examining the relationship between customer misbehavior and emotional labor. Analysis of 21 studies $(\mathrm{N}=12,299)$ met the criteria for inclusion in the meta-analysis. The result of meta-analysis showed: customer misbehavior had significant effects on employee emotional labor. Specifically, customer misbehavior had a positive correlation to surface acting, and had a negative correlation to deep acting. Moderator analyses revealed that cultural difference has significant moderating effects on the relationship between customer misbehavior and emotional labor (including surface acting and deep acting). In addition, the correlation between customer misbehavior and surface acting in the context of China is less than it in the context of other countries.
\end{abstract}

\section{Keywords}

Customer Misbehavior, Emotional Labor, Surface Acting, Deep Acting, Meta-Analysis

\section{Introduction}

The development of the times has changed our lifestyles and the consumption pattern. As a result of the rapid development of China's economy, our lifestyle has undergone tremendous changes. The service industry has played an increasingly important role in our life. "Consumer is the god" philosophy does not allow Chinese and western companies to achieve the desired business performance [1]. However, the service staff in a relatively weak position often faces verbal aggression and embarrassment, and the news about customer misconduct, like "Medical Disputes", occurs frequently. Customer misbehavior will not only bring bad effects to enterprise and other customers, but also cause service staff's physical or psychological pressure, such as employee emotional working, job 
burnout, and turnover. In addition, according to the analysis of occupational supply and demand situation, employee needs of accommodation, catering, domestic and other service industry is on the rise. However, service staff's job burnout, emotional labor, leaving the business will have a negative impact. At present, the high turnover rate of employees in the service industry has become the bottleneck of troubling and restricting the development of the organization. For example, the turnover rate of employees in the call centers has remained at around $15 \%$, and sometimes even as high as $20 \%-25 \%$. Emotional labor has become a key problem by service staff, which greatly affects their behavior and willingness. At present, a large number of studies discussed the employee's turnover intention from the payment, working pressure, training and other factors, apparently ignored the impact of customer behavior [2]. Therefore, the study of customer misbehavior is of practical significance.

\section{Theory and Hypotheses}

\subsection{The Relationship between Customer Misbehavior and Emotional Labor}

In the study of the relationship between misbehavior and emotional labor, different scholars have various opinions. It mainly includes the following research results: 1) customer misbehavior positively affects the employee's surface performance, which is representative of the study: in the Dudenhöffe (2015) study, the verbal violation from the customer's performance positively affects surface performance [3].2) The customer's misconduct has a significant negative impact on the employee's surface performance, and the representative studies are: in examining customer unfair behavior and employee emotional labor relations, the empirical results show that the correlation coefficient between customer unfair behavior and employee surface performance is -0.22 [4]. 3) Customer misbehavior has a positive impact on the deep performance of the staff, Dang (2015) proposed that the unfair behavior has a positive impact on the staff's deep performance [5]. 4) Customer misconduct is negatively related to the deep performance of the employee, and the representative studies are: Song and Liu (2010) suggest that the verbal violation of the customer is positively related to the employee's deep performance [6]. In addition, the customer misconduct only affects the employee's surface performance. However, customer misbehavior does not have a significant impact on the staff's deep performance. The emergence of above different views, maybe due to a variety of factors, such as the validity of scales, the different cultural backgrounds, etc.

In the emotional adjustment model of Sliter (2010), it is suggested that when a person encounters something, it will produce a series of emotional reactions [7]. He believes that when employees encounter some contradictions in the work or unfair things, they will produce some negative emotions. Grandy (2007) suggests that verbal violations from outside, such as from customers, colleagues or superiors, have an impact on customer sentiment [8]. Results from Karatepe (2010) showed that social pressure from customers will make employees feel emotional 
exhaustion [9]. In the process of service exchanges, customer misconduct will make employees feel depressed. The negative emotions of employees will affect the performance of employees, such as job burnout, and turnover. However, the negative emotions of employees do not represent a certain negative performance. As employees in the service industry always keep a face-to-face contact with customers, and service-oriented enterprises have certain requirements on the staff's emotional expression rules, so employees in the face of customer misconduct, will take a certain emotional labor strategy to meet the customer and business's claim.

In order to meet the requirements of corporate emotional expression rules, employees will take a certain emotional labor strategy. However, the specific strategies adopted by the staff are related to their cognitive and emotional regulation of misbehavior events. Surface performance is a strategy employees adopted in order to complete the business requirements. They hide their negative emotions deliberately, and show the same emotion on the surface with the organization required. In the case of superficial performance, the feelings of the staff and the emotions expressed are inconsistent. However, deep performance is a positive process that requires employees to manage inner feelings and behavioral expressions at the same time, so that the inner feelings of the staff are consistent with the emotions expressed. Therefore, deep performance requires more effort and mental resources than the surface performance. Thus, when employees face improper behavior of customers, in order to reduce the emotional consumption, they often tend to choose the strategy of surface performances and reduce the deep performance strategy. In this regard, we make the following assumptions:

H1: Customer misbehavior has a significant positive impact on employee performance.

$\mathrm{H} 2$ : Customer misbehavior has a significant negative impact on the employee's deep performance.

\subsection{Cultural Difference Draws Moderating Effects on the Relationship between Customer Misbehavior and Emotional Labor}

Culture is the sum of the precious spiritual wealth and material wealth of human beings. Under different cultural systems, different countries and races differ in their emotional responses and expressions to different contexts. Culture influences belief and emotion at multiple levels of society [10]. In non-Chinese country, this article mainly refers to the western countries, the quality of service requirements is relatively high, and their management is more stringent and more standardized, and so employees can comply with the requirements of the organization. At the same time, westerners are more in pursuit of "money first", so it is more likely for them to sell their own surface performance for wages. As a result, when employees face the customer misconduct, they will use the surface performance to cover up their own true moods, so that their behavior can meet organizational requirements. 
Chinese are influenced by Confucian culture, which respected the ideological core-"Benevolence and Wisdom". In such a cultural background, Chinese people will see "Considerate, Harmony" as positive beliefs. Therefore, compared to non-Chinese cultural background, customer misbehavior at Chinese cultural context has a weaker influence on employees' emotional labor. Based on the above analysis, we make the following assumptions:

H3: Cultural difference has significant moderating effects on the relationship between customer misbehavior and surface acting. Compared to it at the Chinese cultural background, customer misbehavior at the non-Chinese cultural background has a stronger positive impact on surface acting.

H4: Cultural difference has significant moderating effects on the relationship between customer misbehavior and deep acting. Compared to it at the Chinese cultural background, customer misbehavior at the non-Chinese cultural background has a stronger negative impact on deep acting.

\section{Method}

\subsection{Literature Research and Screening}

Firstly, we reviewed the literature, including Chinese literature and English literature. Mainly in the following ways: 1) Chinese literature searching includes the following three steps: firstly, searching literature which title, keywords, abstract and keywords including "customer misconduct, customer unfair behavior, customer infringement, customer attack behavior, dysfunctional customer behavior, customer abnormal behavior, customer irrational behavior, bad customer, problematic customers, unethical customers, non-cooperative customers, jackleg customers, social pressure from customers" and "emotional labor, deep performance, surface performances, mood disorder" in Chinese Journal Net (CNKI database), China Science and Technology Journal Database (Wikipedia), Wanfang database search system, and Google academic search. Secondly, we retrieved 19 journals about management and psychology manually to get literature about this meta-analysis. Finally, in order to avoid missing, we make a search about scholars who have done long-term research in this field. 2) English literature retrieve includes the following three steps: firstly, searching literature include "customer misconduct, customer unfair behavior, customer infringement, customer attack behavior, dysfunctional customer behavior, customer abnormal behavior, customer irrational behavior, bad customer, problematic Customers, unethical customers, non-cooperative customers, jackleg customers, social pressure from customers" and "emotional labor, deep performance, surface performances, mood disorder" in EBSCO, AB1/INFORM, Elsevier Science Direct, Proquest, the web of science and Google Scholar. Next, we invited foreign friends for more detailed literature retrieval. At last, to ensure the literature not missing, we consulted the journals which often publish article about customer irrational behavior and emotional labor frequently.

Secondly, we screened all literates that we had retrieved, the standard of screening is as follows: 1) Screening all empirical literature, removing all non- 
empirical literature. 2) Screening out the main part of emotional labor is employer. 3) Screening out the correlation coefficient between customer misconduct and emotional labor and p-values, or T-values and sample size, or the data of $\mathrm{T}$ value, standard error, variance and correlation coefficient are analyzed. 4) Reviewing whether or not the same researches exist is published in stages, if it exists, it is considered the same research.

The time span of the literature search is between January 1990 and October 2016, we took out the literature that didn't meet the requirements. Finally, we got 21 papers, which include nine English literature, seven Chinese literature and five doctoral dissertations. 21 independent samples of 21 literates were used in this meta-analysis, the sample size is 12299 employees [11].

\subsection{Coding}

Coding standards: 1) The staff tested in this research must be the employee, not the customer or the manager. 2) The research situations occur in the workplace, where the employee and the customers meet face-to-face, and it doesn't include contact by phone or email. 3) The measure of emotional labor consists only of subjective elements, not including emotional labor perceived by others. 4) The independent samples are served as unit of effective values. 5) To collect as complete of dataset as possible, for each document that conforms to the inclusion criteria, we record its important effective values.

Coding process: To extracting the literature date from the meta-analysis, we produced the data encoding table, which included study description item and the effective values statistics. The characteristics of the study include the author, the year of publication, the name of the journal, the sample size, the research method, the measurement method, the study object, the sample characteristics (industries, countries, etc), the study conclusion, and so on. Effective values refer to that the statistics of the double variable correlation coefficient as the center, mainly includes the correlation coefficient between the variables, significance level and the relevant variables of the reliability and validity. Because of the heavy workload of the above coding, the coding work of this study was carried by two authors independently, then proofread and discussed, and finally reached consensus.

\subsection{Statistical Analysis}

In this study, R3.3.1 statistical software was used for meta-analysis. The main contents include:

Effective value calculation: In the meta-analysis, we choose " $r$ " as the effective value. We do not use the $r$ value directly in the calculation because the variance of " $r$ " is too dependent on the correlation. ${ }^{1}$ We transform the $r$ values of the independent samples into $\mathrm{z}$ value by Fisher's $\mathrm{Z}$ transformation as most scholars do that, and then convert it back to the correlation coefficient as a result to show. Table 1 reports the partial coding information of the 21 articles included

${ }^{1} \mathrm{R}$ is a single correlation coefficient or the average correlation coefficient in the literature. 
Table 1. Part of the coding information and comprehensive effect of the results.

\begin{tabular}{|c|c|c|c|c|c|c|c|c|}
\hline & Name & $\begin{array}{l}\text { Country } \\
\text { or region }\end{array}$ & Year & Acting & $\mathrm{N}$ & $\begin{array}{l}\text { Primitive effect } \\
\text { value }\end{array}$ & $\begin{array}{l}\text { Transformed } \\
\text { effect value }\end{array}$ & Source \\
\hline 1 & Zhe Liu & China & 2016 & Surface & 222 & 0.395 & 0.417710618 & $\begin{array}{l}\text { Liu et al., 2016, } \\
\text { East China Economic } \\
\text { Management }\end{array}$ \\
\hline 2 & Jia Zhou & China & 2012 & Surface & 288 & 0.214 & 0.21735959 & $\begin{array}{l}\text { Zhou, 2012, } \\
\text { Master's Degree Thesis of } \\
\text { Northeastern University }\end{array}$ \\
\hline 3 & Xiangyang Gang & China & 2013 & Surface & 380 & 0.589 & 0.676133476 & $\begin{array}{l}\text { Gang, 2013, Master's } \\
\text { Degree Thesis of } \\
\text { Southwest University } \\
\text { of Political } \\
\text { Science and Law }\end{array}$ \\
\hline 4 & $\begin{array}{l}\text { Guoping } \\
\text { Song }\end{array}$ & China & 2010 & Surface & 310 & 0.17 & 0.171666664 & $\begin{array}{l}\text { Song et al., 2010, } \\
\text { Social Behavior } \\
\text { \& Personality }\end{array}$ \\
\hline 5 & Yong Yang & China & 2013 & Surface & 270 & 0.319 & 0.330533423 & $\begin{array}{l}\text { Yang et al., 2013, } \\
\text { Technolog Economics }\end{array}$ \\
\hline 6 & Xiaoyang Li & China & 2013 & Surface & 800 & 0.14 & 0.140925576 & $\begin{array}{l}\text { Li, 2013, Doctoral Thesis of } \\
\text { Huazhong University of } \\
\text { Science and Technology }\end{array}$ \\
\hline 7 & Qing Chen & China & 2014 & Surface & 310 & 0.1 & 0.100335348 & $\begin{array}{l}\text { Chen, 2014, Chinese } \\
\text { Medical Ethics }\end{array}$ \\
\hline 8 & $\mathrm{Lu} \mathrm{Li}$ & China & 2014 & Surface & 487 & 0.61 & 0.708921359 & $\begin{array}{c}\mathrm{Li}, 2014, \text { Master's } \\
\text { Degree Thesis of Xinxiang } \\
\text { Medical University }\end{array}$ \\
\hline 9 & $\begin{array}{l}\text { Yuting } \\
\text { Dang }\end{array}$ & China & 2015 & Surface & 186 & 0.33 & 0.342828254 & $\begin{array}{l}\text { Dang, 2015, Master's } \\
\text { Degree Thesis of } \\
\text { Lanzhou University }\end{array}$ \\
\hline 10 & Sarah Dudenhöffer & Germany & 2015 & Surface & 4130 & 0.43 & 0.459896681 & $\begin{array}{c}\text { Dudenhöffer et al., 2015, } \\
\text { Journal of Personnel } \\
\text { Psychology }\end{array}$ \\
\hline 11 & Osman M & Turkey & 2008 & Surface & 204 & 0.357 & 0.373443468 & $\begin{array}{c}\text { Karatepe et al., 2008, } \\
\text { International Journal of } \\
\text { Contemporary Hospitality } \\
\text { Management }\end{array}$ \\
\hline 12 & Deborah E & Germany & 2008 & Surface & 152 & 0.42 & 0.447692024 & $\begin{array}{l}\text { Rupp et al., 2008, } \\
\text { Journal of Management }\end{array}$ \\
\hline 13 & Grandey & U.S. & 2007 & Surface & 121 & 0.18 & 0.181982689 & $\begin{array}{l}\text { Grandey et al., 2007, } \\
\text { Journal of Occupational } \\
\text { Health Psychology }\end{array}$ \\
\hline 14 & $\begin{array}{c}\text { Junchen } \\
\mathrm{Hu}\end{array}$ & China & 2009 & Surface & 424 & 0.096 & 0.096296554 & $\begin{array}{c}\text { Hu et al., } 2009, \\
\text { Psychological Science }\end{array}$ \\
\hline 15 & Li Zhang & China & 2013 & Surface & 197 & 0.251 & 0.256479763 & $\begin{array}{l}\text { Zhang et al., 2013, Journal } \\
\text { of Management Science }\end{array}$ \\
\hline 16 & Xiaojun Zhan & China & 2014 & Surface & 348 & 0.346 & 0.360892579 & $\begin{array}{c}\text { Zhan, 2014, } \\
\text { Contemporary } \\
\text { Finace and Economics }\end{array}$ \\
\hline
\end{tabular}




\section{Continued}

\begin{tabular}{|c|c|c|c|c|c|c|c|c|}
\hline 17 & Lishan Xie & China & 2011 & Surface & 248 & 0.35 & 0.365443754 & $\begin{array}{l}\text { Xie et al., 2011, Chinese } \\
\text { Journal of Management }\end{array}$ \\
\hline 18 & $\begin{array}{l}\text { Michael } \\
\text { Sliter }\end{array}$ & U.S. & 2010 & Surface & 120 & 0.3 & 0.309519604 & $\begin{array}{c}\text { Sliter et al., 2010, Journal } \\
\text { of Occupational Health } \\
\text { Psychology }\end{array}$ \\
\hline 19 & Huey-hong Hsieh & Taiwan & 2016 & Surface & 195 & 0.536 & 0.598526181 & $\begin{array}{c}\text { Hsieh et al. 2016, } \\
\text { International Journal of } \\
\text { Qrganizational Innovation }\end{array}$ \\
\hline 20 & $\begin{array}{c}\text { Peter } \\
\text { Totterdell }\end{array}$ & U.K. & 2003 & Surface & 18 & 0.5 & 0.549306144 & $\begin{array}{l}\text { Totterdell et al., 2003, } \\
\text { Journal of Occupational } \\
\text { Health Psychology }\end{array}$ \\
\hline 21 & Xiangyang Gang & China & 2013 & Deep & 380 & -0.394 & -0.4165263 & $\begin{array}{l}\text { Gang, 2013, } \\
\text { Master's Degree Thesis of } \\
\text { Southwest University of } \\
\text { Political Science and Law }\end{array}$ \\
\hline 22 & $\begin{array}{l}\text { Guoping } \\
\text { Song }\end{array}$ & China & 2010 & Deep & 310 & -0.12 & -0.12058103 & $\begin{array}{l}\text { Song et al., 2010, Social } \\
\text { Behavior \& Personality An } \\
\text { International Journal }\end{array}$ \\
\hline 23 & Yong Yang & China & 2013 & Deep & 270 & -0.328 & -0.34058549 & $\begin{array}{c}\text { Yang et al., 2013, } \\
\text { Technolog Economics }\end{array}$ \\
\hline 24 & Xiaoyang Li & China & 2013 & Deep & 800 & -0.12 & -0.12058103 & $\begin{array}{c}\text { Li, } 2013 \text {, } \\
\text { Doctoral thesis of } \\
\text { Huazhong University of } \\
\text { Science and Technology }\end{array}$ \\
\hline 25 & Qing Chen & China & 2014 & Deep & 310 & -0.12 & -0.12058103 & $\begin{array}{c}\text { Chen, 2014, } \\
\text { Chinese Medical Ethics }\end{array}$ \\
\hline 26 & $\mathrm{Lu} \mathrm{Li}$ & China & 2014 & Deep & 487 & -0.147 & -0.14807278 & $\begin{array}{l}\text { Li, 2014, Master's Degree } \\
\text { Thesis of Xinxiang } \\
\text { Medical University }\end{array}$ \\
\hline 27 & Deborah E & & 2006 & Deep & 123 & -0.18 & -0.18198269 & $\begin{array}{l}\text { Rupp et al., 2006, } \\
\text { Journal of Applied } \\
\text { Psychology }\end{array}$ \\
\hline 28 & Junchen $\mathrm{Hu}$ & China & 2009 & Deep & 424 & 0.25 & 0.255412812 & $\begin{array}{c}\text { Hu et al., 2009, } \\
\text { Psychological Science }\end{array}$ \\
\hline 29 & Li Zhang & China & 2013 & Deep & 197 & 0.181 & 0.183016366 & $\begin{array}{l}\text { Zhang et al., 2013, } \\
\text { Journal of } \\
\text { Management Science }\end{array}$ \\
\hline 30 & Xiaojun Zhan & China & 2014 & Deep & 348 & -0.452 & -0.48721095 & $\begin{array}{c}\text { Zhan, 2014, } \\
\text { Contemporary } \\
\text { Finace and Economics }\end{array}$ \\
\hline 31 & Lishan Xie & China & 2011 & Deep & 248 & -0.19 & -0.19233717 & $\begin{array}{l}\text { Xie et al., 2011, } \\
\text { Chinese Journal } \\
\text { of Management }\end{array}$ \\
\hline 32 & $\begin{array}{c}\text { Peter } \\
\text { Totterdell }\end{array}$ & U.K. & 2003 & Deep & 18 & 0.39 & 0.411800034 & $\begin{array}{c}\text { Totterdell et al., 2003, } \\
\text { Journal of Occupational } \\
\text { Health Psychology }\end{array}$ \\
\hline
\end{tabular}

Note: Only the first author is listed. 
in the analysis, and the corresponding effective values for each study. Equation (1) is the formula of Fisher's $\mathrm{Z}$ transformation:

$$
z=0.5 \times \ln \left(\frac{1+r}{1-r}\right)
$$

Homogeneity test: Homogeneity test is also called consistency or heterogeneity test, according to the results of the test to select a fixed model or random model. The homogeneity test, based on the $\mathrm{Q}$ statistic and the $\mathrm{Q}$ test, obeys the $\chi^{2}(k-1)$ distribution [12]. If the $\mathrm{Q}$ statistic is not significant, the results of the two models are similar. However, if the $\mathrm{Q}$ test statistic is near the critical value, the stochastic model and the fixed model were chosen and the differences in the parameters of the two models were compared, making the conclusion of the meta-analysis more reliable [13]. We can directly receive random model and fixed model through the R software.

Merging analysis: Meta-analysis requires that the results of multiple independent studies be combined into a single effective value, which is a combined statistic to reflect the combined effect of multiple independent samples. A hypothesis test is made on the combined statistics to see whether the combined statistics are statistically significant.

Publication bias checking: The studies that results are not significant are difficult to be published, so the meta-analysis is heavily dependent on the published results, and thus it may appear publication bias problem. In order to estimate the risk of publication bias, many scholars cited the "loss of safety factor" to estimate the number of samples still need to make the effective value being not significant. The greater of the value means that the effective value is more stable, the possibility of publication bias is smaller. ${ }^{2}$

\section{Results}

\subsection{Homogeneity Test}

We conduct homogeneity tests on customer misconduct and employee surface performance, customer misconduct and employee deep performance. According to Table 2, Q-Value is statistically significant, meaning that these effective values obey heterogeneous distribution, which reveals that the effect of customer misconduct on employee surface performance is heterogeneous. Therefore, random model method is used in the study of customer misconduct and employee surface performance. The value of I-squared (I2) is $92.60 \%$, indicating that $92.60 \%$ of the observed variance is due to the real difference in the effective value, and only $7.4 \%$ of the observed variation is caused by random error. In this model, the weighting of individual studies is required, and the use of Tau-squared (T2) is to assign the weights of the studies and adjust the real variation. According to Table 2 , the value of $\left(\tau^{2}\right)$ is 0.0323 , which indicates that $3.23 \%$ of the inter-research variance can be used to calculate the weight.

${ }^{2}$ We calculated the number of safety failures in terms of the relative conservative significant standards $(r=0.10$, Cohen, 1969). 
Table 2. Specific results of the meta-analysis.

\begin{tabular}{|c|c|c|c|c|c|c|c|c|c|}
\hline & Model & K & $\mathrm{N}$ & $\begin{array}{c}\text { Point } \\
\text { estimation }\end{array}$ & $95 \% \mathrm{CI}$ & Z-Value & Q-Value & $\mathrm{I}^{2}$ & $\tau^{2}$ \\
\hline \multirow{2}{*}{$\mathrm{H} 1$} & $\begin{array}{l}\text { Fixed } \\
\text { effect }\end{array}$ & 20 & 9410 & 0.3692 & $0.3516-0.3866$ & $37.47^{\star \star \star}$ & $255.41^{\star * *}$ & $92.60 \%$ & 0.0323 \\
\hline & $\begin{array}{c}\text { Random } \\
\text { effect }\end{array}$ & 20 & 9410 & 0.3362 & $0.2589-0.4092$ & $8.08^{* * *}$ & & & \\
\hline \multirow{2}{*}{$\mathrm{H} 2$} & $\begin{array}{l}\text { Fixed } \\
\text { effect }\end{array}$ & 12 & 3915 & -0.1478 & $(-0.1784)-(-0.1169)$ & $-9.27^{\star * *}$ & $172.93^{* * *}$ & $93.60 \%$ & 0.047 \\
\hline & $\begin{array}{c}\text { Random } \\
\text { effect }\end{array}$ & 12 & 3915 & -0.1313 & $(-0.2564)-(-0.0019)$ & $-1.99^{*}$ & & & \\
\hline
\end{tabular}

Notes: a. $\mathrm{H} 1$ indicates the meta-analysis of the relationship between customer misbehavior and surface acting; $\mathrm{H} 2$ indicates the meta-analysis of the relationship between customer misbehavior and deep acting. b. ${ }^{*} p$ $<0.05 ;{ }^{* *} p<0.01 ;{ }^{* * *} p<0.001$.

The results of Table 2, show that the effect of customer misbehavior on employee's deep performance is heterogeneous as Q-Value is statistically significant. Therefore, this paper uses the method of stochastic model to study the effect of heterogeneity in the study of customer misconduct and employee's deep performance. The value of I-squared (I2) is $93.60 \%$, indicating that $93.60 \%$ of the observed variance is due to the real difference in the effect value, and only $6.4 \%$ of the observed variance is caused by random errors. According to Table $2,\left(\tau^{2}\right)$ is 0.047 , which indicates that $4.7 \%$ of the inter-research variability can be used to calculate the weight [14].

\subsection{The Overall Effect of the Relationship between Improper Behavior and Emotional Labor}

The results of Table 2, show the random effects and fixed effect models of the relationship between customer misconduct and emotional labor. Based on homogeneity analysis, we use the stochastic effect model to analyze this relationship. As shown in Table 2, the correlation between customer misconduct and surface performance is 0.3362 , which is medium-intensity relevant. However, the correlation between customer misconduct and deep performance is -0.1313 , which is related to low intensity. ${ }^{3}$

Due to the above result is significant, the hypothesis 1 and the hypothesis 2 have to be supported. In other words, customer misbehavior had a significant positive correlation to surface acting, and had a significant negative correlation to deep acting.

\subsection{Moderating Effects on the Relationship between Customer Misbehavior and Emotional Labor}

Table 3 indicates a meta-analysis of cultural background's moderating effect on the relationship between customer misbehavior and employee's emotional labor

${ }^{3}$ Ipsey \& Wilson (2008, p. 123) pointed out that "if the effective value of the correlation coefficient less than or equal to 0.10 can be considered small; the value is equal to 0.25 can be regarded as medium; the value is greater than or equal to 0.40 can be considered large". 
Table 3. Meta-analysis of cultural background's moderating effect.

\begin{tabular}{|c|c|c|c|c|c|c|c|}
\hline EL & $\begin{array}{c}\text { Moderator } \\
\text { Variable }\end{array}$ & Q-Value & Types & $S$ & $\mathrm{~N}$ & Effect size and $0.95 \mathrm{CI}$ & Z-Value \\
\hline \multirow{2}{*}{ Surface } & \multirow{4}{*}{$\begin{array}{c}\text { Cultural } \\
\text { differences }\end{array}$} & $196.12^{* * *}$ & Chinese & 12 & 4284 & $\begin{array}{c}\text { Fixed effect: } 0.3054 \\
\quad(0.2778,0.3324) \\
\text { Random effect: } 0.3099 \\
(0.1896,0.4210)\end{array}$ & $\begin{array}{c}\text { Fixed: } \mathrm{Z}=20.56, \\
P<0.0001 \\
\text { Random: } \mathrm{Z}=4.89, \\
P<0.0001\end{array}$ \\
\hline & & $18.82^{\star *}$ & Non-Chinese & 9 & 5126 & $\begin{array}{c}\text { Fixed effect: } 0.4199 \\
(0.3970,0.4422) \\
\text { Random effect: } 0.3848 \\
(0.3152,0.4504)\end{array}$ & $\begin{array}{c}\text { Fixed: } \mathrm{Z}=31.97, \\
P<0.0001 \\
\text { Random: } \mathrm{Z}=10.01, \\
P<0.0001\end{array}$ \\
\hline \multirow{2}{*}{ Deep } & & $168.08^{* * *}$ & Chinese & 10 & 3774 & $\begin{array}{c}\text { Fixed effect: }-0.1499 \\
(-0.1801,-0.1175) \\
\text { Random effect: }-0.1503 \\
(-0.2838,-0.0111)\end{array}$ & $\begin{array}{c}\text { Fixed: } \mathrm{Z}=-9.18, \\
P<0.0001 \\
\text { Random: } \mathrm{Z}=-2.12, \\
P=0.0344\end{array}$ \\
\hline & & $4.70^{*}$ & Non-Chinese & 2 & 141 & $\begin{array}{l}\text { Fixed effect: }-0.1155 \\
\quad(-0.2772,0.0526) \\
\text { Random effect: } 0.0657 \\
\quad(-0.4685,0.5647)\end{array}$ & $\begin{array}{c}\text { Fixed: } \mathrm{Z}=-1.35, \\
P=0.1777 \\
\text { Random: } \mathrm{Z}=-0.22, \\
P=0.8222\end{array}$ \\
\hline
\end{tabular}

Notes: $(1)^{\star} p<0.05 ;{ }^{* *} p<0.01 ;{ }^{* *} p<0.001$.

(including deep acting and surface acting). According to the results in Table 3, we conclude that cultural differences have a moderating effect on the relationship between customer misconduct and employee surface performance, which is that compared to it at the Chinese cultural background, customer misbehavior at the non-Chinese cultural background has a stronger positive impact on surface acting. In addition, the cultural differences also have a moderating effect on the relationship between customer misconduct and employee deep performance. However, it cannot be drawn that which one of these cultural backgrounds has a stronger effect on the relationship between customer misbehavior and employee's deep acting. We explain this situation is caused by insufficient sample size. Therefore, H3 is supported and $\mathrm{H} 4$ is partly supported.

\section{Discussion and Analysis}

Under the situation that customer has a face-to-face contact with employees; we had an empirical literature review on the study about customer misbehavior and employees' emotional labor. According to our quantitative results, as follows: 1) customer misconduct has a significantly positive correlation with employee surface performance, and the correlation coefficient of 0.3362. Customer misbehavior can cause employees' negative emotions, but in order to their behavior to be consistent with the requirements of the organization, employees have to hide their negative emotions, resulting in the situation that their expression is inconsistent with their real thoughts. 2) There was a significant negative correlation between customer misbehavior and employee's deep performance, with a correlation coefficient of -0.1313 . Deep acting is a positive expression that the result of staff managing their emotions. Therefore, their expression is consistent with 
their hearts. However, it is difficult for employees to transfer their negative emotions into positive emotions in order to align with organizational goals, which means that it is difficult for employees to achieve deep performance. 3) Cultural differences have a moderating effect on the relationship between customer misbehavior and employee surface performance. In the Chinese context, the correlation coefficient between customer misconduct and employee surface performance is 0.3099 , which is less than 0.3848 in non-Chinese context. Therefore, the staff in non-Chinese background tends to present surface acting more easily when they meet customer misbehavior. 4) Cultural differences have a regulatory effect on the relationship between customer misbehavior and employee's deep performance.

According to the results of our meta-analysis, we give some advice to the service organization: 1) "Custom is the god" philosophy becomes the service purpose of many enterprises, but the customer misbehavior has different negative impact on the enterprises, the other customers and the employees. The occurrence of customer improper behavior is often derived from service staff and customers having difference in social status. Therefore, enterprises should define the rights of customers, narrowing the gap between the rights of customers and enterprises to promote mutual respect and understanding. 2) The previous employee training is limited to the skills training. Since the customer misbehavior has a significant impact on employee emotional work, then the enterprise can be training in the training of stress tolerance, so that employees will take a deep acting strategy it the face of negative events. 3) Customer misbehavior has a different impact on employee emotional labor in different cultural backgrounds, so enterprises need to consider the management of cultural background. In addition, compared to the Chinese background, customer misconduct in non-Chinese background has a stronger impact on the staff's surface performance. Therefore, Chinese enterprises should take the cultural characteristics of China into account, and weak the negative effect of customer misconduct on the surface acting by using the positive concept of Confucian culture.

The limitation of this study: 1) It cannot explore if there are other variables have moderating effects on the relationship between customer misbehavior and emotional labor by the restriction of existing literature. 2) This study explores customer misbehavior only from the perspective of staff. However, we can also study customer misbehavior from other perspectives, such as customers, organizations and the other customers. 3) We eliminate some papers which are lack of data in the process of literature screening, resulting the loss of a part of the samples. 4) Because of the difficulty of document acquisition, it is difficult for us to rule out all the literature. The papers used in our study mostly are journal articles. We cannot collect all the conference papers and unpublished articles, so our findings may have some information on the availability of bias [15].

Future research can be carried out from the following aspects: 1) Although scholars on the study of customer misbehavior already get good results, they have not achieved a general conclusion on the definition and name of customer 
misbehavior. In addition, the dimensionality and scale of customer misbehavior are still to be developed. 2) Scholars have been rich in the study of emotional labor, but the dimension of emotional labor is not uniform. Consequently say, it is need sort out the study of emotional labor, so that working out a relatively uniform dimension of the division. 3) In the study of the relationship between customer misconduct and emotional labor, we can continue to explore if there are other variables have moderating effects on the relationship between customer misbehavior and emotional labor. 4) Future research can also explore the mediating effect on the relationship between customer misbehavior and emotional labor.

\section{Conclusions}

The current meta-analysis provides a more accurate estimate of the relationship between customer misconduct and emotional labor:

1) There is a significant positive correlation between customer misbehavior and employee surface acting, with a correlation coefficient of 0.3362 .

2) There is a significant negative correlation between customer misbehavior and employee's deep acting, with a correlation coefficient of -0.1313 .

3) Cultural difference has a significant effect on the relationship between customer misbehavior and emotional labor. Compared to it at the Chinese cultural background, customer misbehavior at the non-Chinese cultural background has a stronger positive impact on surface acting.

\section{References}

[1] Rupp, D.E. and Spencer, S. (2006) When Customers Lash Out: The Effects of Customer Interactional Injustice on Emotional Labor and the Mediating Role of Discrete Emotions. Journal of Applied Psychology, 91, 971-978. https://doi.org/10.1037/0021-9010.91.4.971

[2] Brecher, B. (1990) The Kidney Trade: Or, the Customer Is Always Wrong. Journal of Medical Ethics, 16, 120-123. https://doi.org/10.1136/jme.16.3.120

[3] Li, X.Y. and Zhou, E.H. (2012) Influence of Customer Verbal Aggression on Employee Turnover Intention in a Service Business: Psychological Capital as a Moderator. Nankai Business Review, 15, 39-47.

[4] Dudenhöffer, S. and Dormann, C. (2015) Customer-Related Social Stressors: Meaning and Consequences across Service Jobs. Journal of Personnel Psychology, 14, 165-181. https://doi.org/10.1027/1866-5888/a000132

[5] Dang, Y. (2015) Service Climate and Front-Line Employees Emotional Labor: The Mediating Role of Excellent Service Role Identity. Lanzhou University, Lanzhou.

[6] Song, G. and Liu, H. (2010) Customer-Related Social Stressors and Emotional Exhaustion: The Mediating Role of Surface and Deep Acting. Social Behavior \& Personality: An International Journal, 38, 1359-1366. https://doi.org/10.2224/sbp.2010.38.10.1359

[7] Sliter, M., Jex, S., Wolford, K. and Mcinnerney, J. (2010) How Rude! Emotional Labor as a Mediator between Customer Incivility and Employee Outcomes. Journal of Occupational Health Psychology, 15, 468-481. https://doi.org/10.1037/a0020723

[8] Grandey, A.A., Kern, J.H. and Frone, M.R. (2007) Verbal Abuse from Outsiders 
versus Insiders: Comparing Frequency, Impact on Emotional Exhaustion, and the Role of Emotional Labor. Journal of Occupational Health Psychology, 12, 63. https://doi.org/10.1037/1076-8998.12.1.63

[9] Karatepe, O.M., Yorganci, I. and Haktanir, M. (2009) An Investigation of the Role of Job Resources in Mitigating Customer-Related Social Stressors and Emotional Exhaustion. Services Marketing Quarterly, 31, 72-88. https://doi.org/10.1080/15332960903408476

[10] Koman, E.S., Wolff, S. and Howard, A. (2008) The Cascading Impact of Culture: Group Emotional Competence (GEC) as a Cultural Resource. Emotional Intelligence: Theoretical and Cultural Perspectives, 26, 39-53.

[11] Zhang, H. and Li, D. (2012) A Meta-Analysis on the Relationship between High Performance Work System and Firm Performance in the Context of China. Nankai Business Review, 5.

[12] Lipsey, M.W. and Wilson, D.B. (2004) Practical Meta-Analysis. Sage, Thousand Oaks.

[13] Marin-Martinez, F. and Sanchez-Meca, J. (2010) Weighting by Inverse Variance or by Sample Size in Random-Effects Meta-Analysis. Educational and Psychological Measurement, 70, 56-73. https://doi.org/10.1177/0013164409344534

[14] Huang, J., Brink, H.M.V.D. and Groot, W. (2009) A Meta-Analysis of the Effect of Education on Social Capital. Economics of Education Review, 28, 454-464.

[15] Hunter, J.E. (2006) Methods of Meta-Analysis. BMS Bulletin of Sociological, 91, 48-49.

\section{Submit or recommend next manuscript to SCIRP and we will provide best} service for you:

Accepting pre-submission inquiries through Email, Facebook, LinkedIn, Twitter, etc. A wide selection of journals (inclusive of 9 subjects, more than 200 journals)

Providing 24-hour high-quality service

User-friendly online submission system

Fair and swift peer-review system

Efficient typesetting and proofreading procedure

Display of the result of downloads and visits, as well as the number of cited articles

Maximum dissemination of your research work

Submit your manuscript at: http://papersubmission.scirp.org/

Or contact jss@scirp.org 